\title{
A EXPANSÃO DA EDUCAÇÃO SUPERIOR PRESENCIAL EM SANTA CATARINA (1990-2016)
}

AN EXPANSION OF HIGHER EDUCATION IN THE FACE-TO-FACE

MODALITY IN SANTA CATARINA (1990-2016)

\section{LA EXPANSIÓN DE LA EDUCACIÓN SUPERIOR PRESENCIAL EN \\ SANTA CATARINA (1990-2016)}

\section{Sherlon Cristina De Bastiani ${ }^{1}$ Joviles Vitório Trevisol ${ }^{2}$}

\begin{abstract}
RESUMO: O presente artigo apresenta os resultados de uma pesquisa sobre as dinâmicas de desenvolvimento da educação superior no estado de Santa Catarina. De modo especial, este artigo pretende analisar como se estabelece o atual panorama da graduação na modalidade presencial em Santa Catarina e, com isso, analisa em retrospectiva como esta modalidade vem evoluindo ao longo dos anos. O estudo foi desenvolvido no período entre agosto de 2015 a julho de 2017. Foram utilizados procedimentos e técnicas quantitativas e qualitativas. A pesquisa bibliográfica e documental foi desenvolvida por meio de livros, artigos, teses, dissertações, relatórios e documentos. Os dados quantitativos foram obtidos na base de dados do INEP, informações do IBGE, consulta aos endereços eletrônicos das instituições de ensino superior pesquisadas e por meio de pedidos de informações via correio eletrônico. Entre outras conclusões, o estudo demonstra que a expansão do ensino superior catarinense se deu, inicialmente, por meio das fundações educacionais de direito privado o que também contribuiu para uma predominância de IES privadas no estado. Do total de IES em 2016, 94\% eram privadas (com e sem fins lucrativos), setor que respondia nesse ano por 68,2\% das matrículas de graduação presencial.
\end{abstract}

PALAVRAS-ChAVE: Políticas educacionais. Educação superior. Expansão. Santa Catarina.

ABSTRACT: This article presents the results of a research about the development dynamics of higher education in the State of Santa Catarina. In a special way, this article intends to analyze how the current panorama of the graduation in the face modality in Santa Catarina is established and, with this, it analyzes in retrospect how this modality has been evolving over the years. The study was developed between August 2015 and July 2017. Quantitative and qualitative procedures and techniques were used. Bibliographical and documentary research was developed through books, articles, theses, dissertations, reports and documents. The quantitative data were obtained from the database of INEP, information from IBGE, consultation of the electronic addresses of the higher education institutions surveyed and by means of requests for information via electronic mail. Among other conclusions, the study shows that the expansion of higher education in Santa Catarina occurred initially through educational foundations under private law, which also contributed to a predominance of private institutions in the state. Of all higher education institutions in 2016, 94\% were private (for-profit and not-forprofit), which accounted for $68.2 \%$ of undergraduate enrollment in that year.

KEYWORDS: Educational policies. Higher education. Expansion. Santa Catarina.

RESUMEN: El presente artículo presenta los resultados de una investigación acerca de las dinámicas de desarrollo de la educación superior en el estado de Santa Catarina. De manera especial, este artículo pretende analizar cómo se establece el actual panorama de la graduación en la modalidad presencial en Santa Catarina y, con ello, analiza en retrospectiva cómo esta modalidad viene evolucionando a lo largo de los años. El estudio fue desarrollado en el período entre agosto de 2015 a julio de 2017. Se utilizaron procedimientos y técnicas

Submetido em: 08/03/2018 - Aceito em: 05/04/2018 - Publicado em: 29/05/2018.

\begin{tabular}{l|l|l|l|l|l} 
(C) Rev. Inter. Educ. Sup. & Campinas, SP & v.4 & n.3 & p.558-579 & set./dez. 2018
\end{tabular}


cuantitativas y cualitativas. La investigación bibliográfica y documental fue desarrollada por medio de libros, artículos, tesis, disertaciones, informes y documentos. Los datos cuantitativos fueron obtenidos en la base de datos del INEP, informaciones del IBGE, consulta a las direcciones electrónicas de las instituciones de enseñanza superior investigadas y por medio de solicitudes de informaciones vía correo electrónico. Entre otras conclusiones, el estudio demuestra que la expansión de la enseñanza superior de Santa Catarina se dio, inicialmente, por medio de las fundaciones educativas de derecho privado lo que también contribuyó a un predominio de IES privadas en el estado. Del total de IES en 2016, el 94\% eran privadas (con y sin fines de lucro), sector que respondía en ese año por el $68,2 \%$ de las matriculas de graduación presencial.

PAlABRAS Clave: Políticas educativas. Educación universitaria. Expansión. Santa Catarina.

\section{INTRODUÇÃo}

O estado de Santa Catarina completou, em 2017, o primeiro centenário do primeiro curso de nível superior implantado na cidade de Florianópolis. O aniversário de cem anos enseja curiosidades e estimula múltiplas indagações sobre as escolhas e os caminhos trilhados. $\mathrm{O}$ passado, neste caso, reveste-se de particular importância na medida em que revela aspectos primorosos do tempo presente. As transformações não foram pequenas, sobretudo as ocorridas a partir de 1960. A despeito de ser um estado pequeno, com uma população estimada em 7.001.161 habitantes (IBGE, 2017), a educação superior expandiu de tal maneira que o estado respondia, em 2017, pela sétima colocação no país quanto ao número de cursos presenciais de graduação ofertados. De acordo com os dados do INEP, em 2016 existiam 1.448 cursos de graduação presenciais, com 230.267 estudantes matriculados (MEC/INEP, 2017). A expansão se acentuou nas últimas décadas. Entre 1990 e 2016 o número de IES (instituições de ensino superior) em Santa Catarina cresceu 370\%. A maior expansão se deu entre 2000 e 2005, um crescimento de 135,7\% (MEC/INEP, 2015).

A despeito do estado de Santa Catarina ser influenciado diretamente pelas políticas e dinâmicas nacionais, há especificidades no âmbito estadual que, dada a importância ao longo do tempo, precisam ser devidamente reconhecidas e analisadas. A expansão está longe de ser homogênea e uniforme. Os ritmos e as escalas variaram ao longo das décadas e lugares. Os contextos e as dinâmicas locais e regionais ocupam um papel importante; eles incidem em todo o processo de concepção, formulação e implementação das políticas públicas. As políticas educacionais, neste sentido, também são perpassadas pelas dimensões de tempo e de espaço. Elas não podem ser compreendidas adequadamente sem que sejam levadas em consideração as variáveis políticas, econômicas, sociais e culturais, pois elas produzem especificidades de acordo com as características de cada região e localidade (SANTOS, 2010).

Este trabalho apresenta os resultados de uma pesquisa sobre o processo de expansão/interiorização da educação superior em Santa Catarina, realizado entre agosto de

\begin{tabular}{l|l|l|l|l|l}
\hline () Rev. Inter. Educ. Sup. & Campinas, SP & v.4 & n.3 & p.558-579 & set./dez. 2018 \\
\hline
\end{tabular}


2015 a julho de 2017 (DE BASTIANI, 2017). Este artigo, de modo particular, apresenta as principais dinâmicas e tendências que caracterizam o desenvolvimento do ensino de graduação na modalidade pressencial em Santa Catarina.

Os dados apresentados resultam da pesquisa bibliográfica, documental e quantitativa. Inúmeros estudos oferecerem a base conceitual e histórica sobre o tema em estudo, cabendo destaque para os trabalhos de Cunha (2007), Saviani (2007), Romanelli (2014), Freitag (1980), Hawerroth (1999), Muniz (2006), Sampaio (2000), Pegoraro (2006, 2013) e Gumbowsky (2004). A pesquisa documental foi desenvolvida a partir de leis, decretos, documentos, relatórios, sítios institucionais, boletins de balanço, livros, artigos, dissertações e teses. Os dados quantitativos foram obtidos junto à base de dados do INEP/MEC. São dados obtidos através do E-Sic: tratam-se de "tabelões" por meio dos quais é possível filtrar e organizar as informações necessárias. Foram consultados, ainda, os dados do IBGE, de sítios eletrônicos das instituições de ensino superior e pedidos feitos via e-mail.

\section{BREVE HISTÓRICO DA EVOLUÇÃO}

A primeira instituição de ensino superior (IES) em Santa Catarina foi criada em 1917. O Instituto Politécnico, sediado em Florianópolis, surgiu da iniciativa de alguns profissionais residentes na capital catarinense, como cirurgiões-dentistas, farmacêuticos, médicos, engenheiros, bacharéis em direito, um oficial da marinha e um guarda-livros. No Instituto funcionavam os cursos de Odontologia, Farmácia, Engenharia e Comércio. Anos mais tarde, professores do próprio Instituto deram origem à Faculdade de Direito, que funcionou por meio de doações até 1934 (PEGORARO, 2006). No ano seguinte, em 1935, a Constituição Estadual estabeleceu que o governo do estado devia assumir a responsabilidade com a condução dessa instituição. Em seu Art. 129, a Constituição Estadual determinou que competia ao "Estado custear o ensino normal e manter ou subvencionar o ginasial, o superior e o profissional de artes e ofícios" (grifo nosso). No mesmo ano, por meio da Lei $\mathrm{n}^{\mathrm{o}} 19$, de 20 de novembro de 1935, a Faculdade de Direito foi estatizada. Três anos depois, o Decreto-Lei $\mathrm{n}^{\mathrm{o}}$ 120, de 9 de junho de 1938, tornou-o instituto "livre e particular". Somente em 1956 a faculdade foi federalizada, ano em que o estado volta a ofertar o ensino superior público. $\mathrm{O}$ movimento da federalização assumia o viés de responsabilização do estado sobre questões públicas, embora o acesso à educação superior da época estivesse à disposição de grupos sociais muito restritos.

As faculdades isoladas foram predominantes no estado até a criação da Universidade Federal de Santa Catarina (UFSC), em 1960. Criada a partir da aglutinação de diferentes faculdades e cursos isolados existentes em Florianópolis, a UFSC introduziu um modelo completamente novo de IES (a universidade). Além de pública e gratuita, a instituição passou a ofertar, além 
do ensino, também a pesquisa e a extensão. A iniciativa, ocorrida 43 anos após a implantação dos primeiros cursos superiores em Florianópolis, teve forte repercussão, particularmente entre as lideranças políticas e educacionais das principais cidades de SC, que já vinham demandando, junto ao governo estadual, a interiorização da educação superior. Os municípios de maior porte econômico passam a pleitear a criação de instituições que viabilizassem a implantação e expansão da educação superior no estado.

A década de 60 coloca-se marcadamente imponente no que diz respeito à expansão e interiorização do ensino superior no estado. Nesta década foi posto em ação o PLAMEG I (1961-1965) - Plano de Metas do Governo - que abrangia o planejamento de todos os setores e, é na área da educação estadual o primeiro plano (VEDANA, 1997). O PLAMEG I trouxe à tona ensejos políticos em prol da expansão do ensino superior, inclusive projetava a possibilidade de ajuda à instituições privadas. Além disso, a partir dele é que foi criado o Fundo Estadual de Educação ${ }^{2}$.

A expansão do ensino superior na década de 60 contou, ainda, com a articulação do Conselho Estadual de Educação (CEE). Como pedido do PLAMEG, o CEE elaborou um estudo para melhorar a qualidade do ensino no estado e, com isso, sugeriu a criação de uma Faculdade para a especialização de professores (VEDANA, 1997). Nesse contexto foi criada a Faculdade de Educação (FAED) - que ofereceu como primeiro curso o de Pedagogia - e, o Centro de Estudos e Pesquisas Educacionais (CEPE) vinculado à Faculdade.

Em 1965 foi criada a Universidade do Estado de Santa Catarina (UDESC) por meio da aglutinação da FAED, do CEPE, da Fundação Educacional de Santa Catarina (FESC) e da Faculdade de Engenharia de Joinville. Destaque-se que a UDESC nasce com um elemento novo: ter um campus sediado fora da capital. Contudo, a inexistência de condições orçamentárias para a expansão das IES públicas para o interior do estado foi fator decisivo para o surgimento de iniciativas regionais que resultaram na criação de instituições privadas sem fins lucrativos.

Trata-se de uma modalidade específica de fundações educacionais, criadas pelo poder público municipal, porém de direito privado, definidas como IES filantrópicas e sem fins lucrativos (FRANTZ, 2004; PEGORARO, 2006; TREVISOL, 2015a). Inserem-se no arco das entidades do "terceiro setor" na medida em que são públicas não-estatais, cuja finalidade principal é promover atividades sem fins lucrativos, de interesse público.

\footnotetext{
${ }^{2}$ O Art. $3^{\circ}$, inciso I, alínea A, da Lei $n^{\circ} 2.772$, de 21 de julho de 1961 regulamenta o Fundo Estadual de Educação da seguinte forma: “[...] a) o Fundo Estadual de Educação, destinado à construção, reconstrução, ampliação e equipamentos de prédios escolares de ensino primário, médio e superior, inclusive aperfeiçoamento, de serviço, melhoria dos padrões pedagógicos e subvenções e ajudas financeiras e técnicas, a entidades particulares ou oficiais de outra órbita, vinculadas ao setor".

\begin{tabular}{l|l|l|l} 
(C) Rev. Inter. Educ. Sup. & Campinas, SP & v.4 & n.
\end{tabular}

\begin{tabular}{l|l}
\hline .3 & p.558-579
\end{tabular}

set./dez. 2018
} 
Entre 1964 a 1986 foram criadas 21 fundações, sendo 20 delas instituídas pelo poder público municipal e 01 (a FESC) pelo legislativo estadual. Apenas entre 1968 a 1976 foram criadas 13 fundações. A FESC, na sequência, por iniciativa do governo estadual, por meio do Decreto $\mathrm{n}^{\circ}$ 2.802, de 20 de maio de 1965, foi transformada na Universidade do Estado de Santa Catarina (UDESC).

As fundações educacionais cresceram de forma exponencial. Em duas décadas a maior parte dos municípios de médio e grande porte contava com oferta de cursos superiores. A expansão do modelo fundacional ensejou, em seguida, um movimento que resultou na transformação das fundações educacionais em universidades. Entre 1986 e 2009 foram criadas treze universidades comunitárias nas principais regiões do estado (PEGORARO, 2013; TREVISOL, 2015b) ${ }^{3}$.

No período entre 1996-2004, o número de IES em Santa Catarina cresceu 347,6\%, passando de 21, em 1996, para 94, em 2004. O crescimento foi cerca de três vezes maior que o ocorrido a nível nacional, e mais de duas vezes superior ao verificado na Região Sul (MEC/INEP/DEAES, 2006, p. 31). A maior expansão se deu entre 2000 e 2005, um crescimento de 135,7\% (MEC/INEP, 2015). O ano de 2003 é particularmente ilustrativo. Em Santa Catarina haviam, neste ano, 81 IES. No ano seguinte, em 2004, esse número saltou para 94 , configurando um crescimento de $16 \%$, índice praticamente o dobro do crescimento médio nacional (Ibid., p. 28).

O setor privado cresceu muito nos anos 90, com essa expansão o setor privado consolidou sua hegemonia no sistema de oferta de ensino superior, caracterizando um ciclo de expansão. Do total de estudantes matriculados em cursos de graduação em 2016 (331.350) o setor público respondia por 22,7\% das matrículas, ou seja, 75.322 matrículas (MEC/INEP, 2016). O setor privado tem impulsionado também a educação a distância. Entre as 101.083 matriculas na modalidade EaD, contabilizadas em 2016, 97,9\% delas estavam em IES privadas.

Na primeira década do século XXI ocorreu o último importante ciclo de expansão. Trata-se do processo de interiorização das IES públicas, impulsionado, em grande parte, pelas políticas do governo federal, particularmente o Programa de Apoio a Planos de Reestruturação e Expansão das Universidades Federais (REUNI), o Programa Universidade Aberta do Brasil

\footnotetext{
${ }^{3}$ No período foram criadas as seguintes instituições de ensino superior: Universidade Regional de Blumenau (1986), Universidade do Vale do Itajaí (1989), Universidade do Sul de Santa Catarina (1989), Universidade do Oeste de Santa Catarina (1995), Universidade da Região de Joinville (1996), Universidade do Contestado (1997) Universidade do Extremo Sul Catarinense (1997), Universidade do Planalto Catarinense (1999), Centro Universitário de Jaraguá do Sul (2000), Universidade da Região do Alto Vale do Itajaí (2001), Universidade Comunitária Regional de Chapecó (2002), Centro Universitário de Brusque (2003), Universidade do Alto Vale do Rio do Peixe (2009). Atualmente a UNERJ vem sendo administrada pela PUC/PR e assume o nome de Católica de Santa Catarina, passando a ser também Centro Universitário e não mais Universidade, mantém, ainda, o mesmo órgão como mantenedora, a Fundação Educacional Regional Jaraguaense.

\begin{tabular}{l|c|c|c|c|c}
\hline C Rev. Inter. Educ. Sup. & Campinas, SP & v.4 & n.3 & p.558-579 & set./dez. 2018
\end{tabular}
}


(UAB) e o Programa de Reestruturação da Rede Federal de Educação Profissional, Científica e Tecnológica. Em 2003, a UDESC (única universidade estadual) aprovou a implantação do Centro de Educação Superior do Oeste (Diário Oficial do Estado, n 17.086, de 31 de janeiro de 2003), autorizando a oferta dos cursos de Zootecnia (Chapecó), Enfermagem (Palmitos) e Engenharia de Alimentos (Pinhalzinho). Em 2009, a UFSC (até então a única universidade federal do estado) aprovou a criação de seus três primeiros campi nas cidades Araranguá, Joinville e Curitibanos. Nesse ano também foi criada a Universidade Federal da Fronteira Sul (UFFS), passando a ser a segunda universidade federal no estado. Como parte desse ciclo cabe destacar também a criação, em 2008, do Instituto Federal de Educação, Ciência e Tecnologia de Santa Catarina (IFSC) e do Instituto Federal de Educação, Ciência e Tecnologia Catarinense IFC).

\section{PERFIL DAS IES CATARINENSES}

De acordo com a pesquisa realizada, em 2016 havia 94 IES ofertando cursos de graduação em Santa Catarina, destas, 88 IES oferecem cursos na modalidade presencial. Entre 1990 e 2016 o número de IES em Santa Catarina cresceu 370\%. A maior expansão se deu entre 2000 e 2005, um crescimento de 135,7\% (MEC/INEP, 2015).

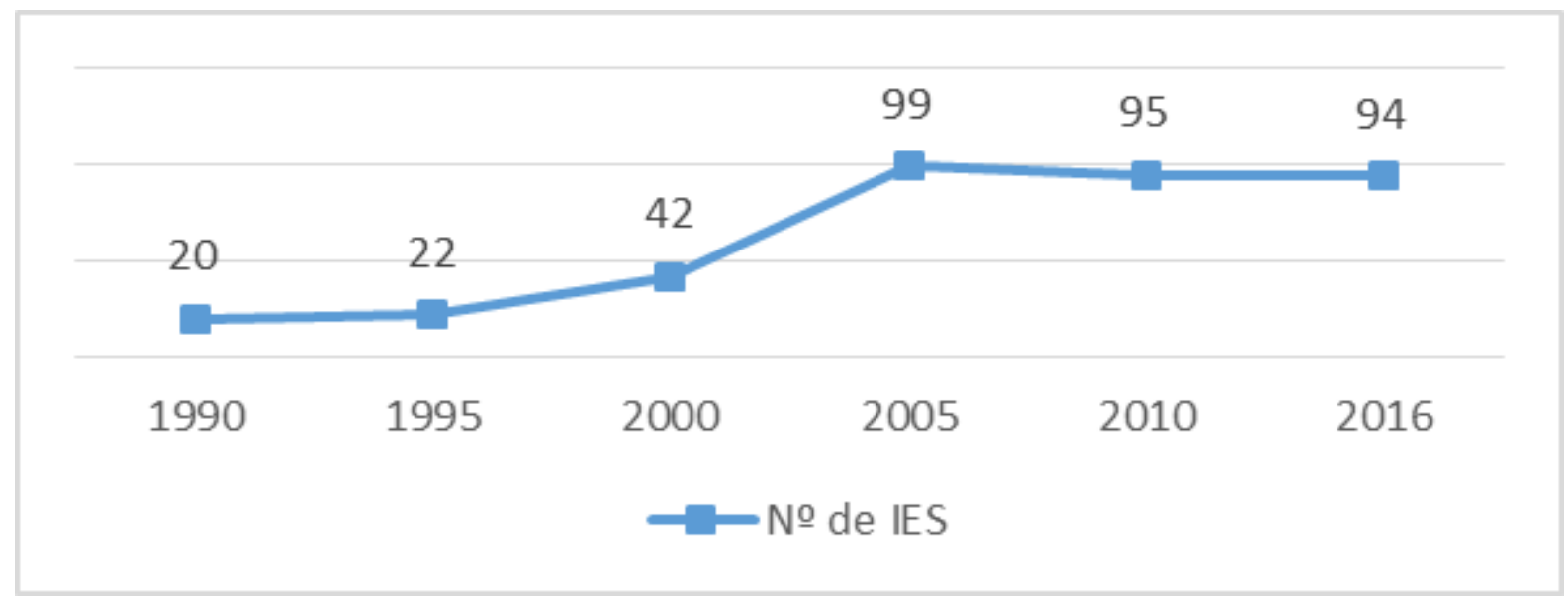

Gráfico 1: Evolução do número de IES em Santa Catarina (1990-2016)

Fonte: elaborado com base nos dados INEP/MEC, 2016.

As instituições privadas (com e sem fins lucrativos) respondiam, em 2016, por $94 \%$ do total das IES. O estado de Santa Catarina, diferentemente de outras unidades da federação, fez clara opção por políticas privatizante de educação superior. O modelo fundacional foi impulsionado desde os anos 60 com o propósito de viabilizar o acesso via financiamento privado. Ao fazê-lo, o poder público retirou de si a responsabilidade pela oferta da gratuidade. As fundações municipais de direito privado foram hegemônicas até os anos 2000, 
momento em que passou a ocorrer a expansão das IES privadas com fins lucrativos e as instituições públicas. As IES públicas e gratuitas correspondiam, em 2016, a apenas $6 \%$ do total de 94 IES com oferta de cursos de graduação presencial em Santa Catarina. Desse percentual, 4\% são IES federais (UFSC, UFFS, IFSC e IFC), 1\% é estadual (UDESC) e 1\% municipal (Faculdade Municipal de São José).

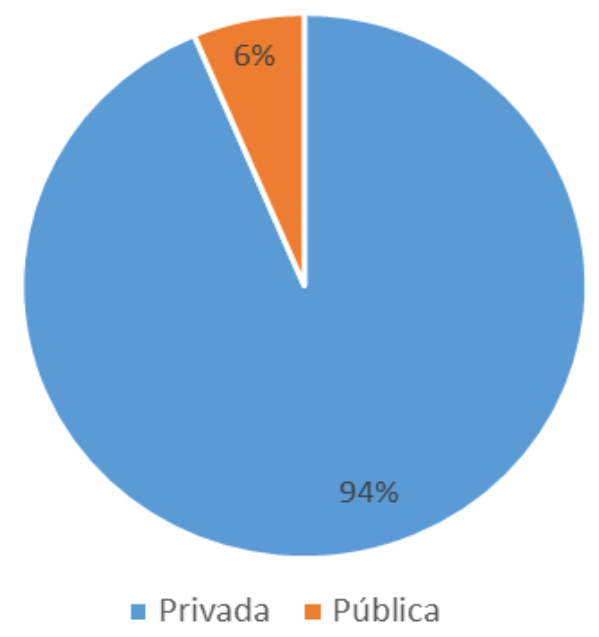

Gráfico 2: Distribuição das IES em Santa Catarina, por dependência administrativa em 2016 Fonte: elaborado com base nos dados MEC/INEP, 2016.

O número de IES públicas, como se pode observar, é bastante pequeno. Até 1989 a UFSC era a única instituição a ofertar ensino público e gratuito no estado, ano que a UDESC interrompeu a cobrança de mensalidades e passou a assegurar o princípio da gratuidade, passando a ser, nos termos dos artigos 39 (das disposições transitórias) e 169 (ensino superior) da nova Constituição estadual, uma instituição pública de direito público.

O quadro a seguir relaciona todas as IES - e suas respectivas cidades e regiões - que ofertavam cursos superiores presenciais em Santa Catarina em 2016.

Quadro 1: IES com oferta de cursos de graduação presencial em Santa Catarina em 2016

\begin{tabular}{|l|l|l|}
\hline \multicolumn{2}{|c|}{ IES PRIVADAS COM FINS LUCRATIVOS } \\
\hline \multicolumn{1}{|c|}{ IES } & CIDADE ORIGEM & \multicolumn{1}{c|}{ REGIÃO } \\
\hline $\begin{array}{l}\text { Centro Universitário Estácio de Santa Catarina - Estácio } \\
\text { Santa Catarina }\end{array}$ & São José & Grande Florianópolis \\
\hline Centro Universitário FACVEST & Lages & Serrana \\
\hline Centro Universitário Leonardo da Vinci & Indaial & Vale do Itajaí \\
\hline Centro Universitário SOCIESC & Joinville & Norte \\
\hline Escola Superior de Criciúma - ESUCRI & Criciúma & Sul \\
\hline Escola Superior de Educação Corporativa - ESEC & São José & Grande Florianópolis \\
\hline Faculdade Barddal & Florianópolis & Grande Florianópolis \\
\hline
\end{tabular}

\begin{tabular}{l|l|l|l|l|l}
\hline (C) Rev. Inter. Educ. Sup. & Campinas, SP & v.4 & n.3 & p.558-579 & set./dez. 2018 \\
\hline
\end{tabular}




\section{IIIIIIII|| Revsta I Iremacional de Educação Superior [RIESup]

\begin{tabular}{|c|c|c|}
\hline Faculdade Capivari & Capivari de Baixo & Sul \\
\hline Faculdade CESUSC & Florianópolis & Grande Florianópolis \\
\hline Faculdade Concórdia & Concórdia & Oeste \\
\hline Faculdade de Ciências Sociais Aplicadas & Xaxim & Oeste \\
\hline Faculdade de Itapiranga & Itapiranga & Oeste \\
\hline Faculdade de Tecnologia em Saúde & Florianópolis & Grande Florianópolis \\
\hline Faculdade de Tecnologia Nova Palhoça & Palhoça & Grande Florianópolis \\
\hline Faculdade de Tecnologia Aero TD & Florianópolis & Grande Florianópolis \\
\hline Faculdade Decisão & Florianópolis & Grande Florianópolis \\
\hline Faculdade do Vale do Itajaí Mirim & Brusque & Norte \\
\hline Faculdade Empresarial de Chapecó & Chapecó & Oeste \\
\hline Faculdade Energia de Administração e Negócios & Florianópolis & Grande Florianópolis \\
\hline Faculdade Jangada & Jaraguá do Sul & Norte \\
\hline Faculdade Leonardo da Vinci - Santa Catarina & Timbó & Norte \\
\hline Faculdade Metropolitana de Blumenau & Blumenau & Norte \\
\hline Faculdade Metropolitana de Guaramirim & Guaramirim & Norte \\
\hline Faculdade Metropolitana de Rio do Sul & Rio do Sul & Vale do Itajaí \\
\hline Faculdade Metropolitana do Planalto Norte & Canoinhas & Norte \\
\hline Faculdade Pinhalzinho & Pinhalzinho & Oeste \\
\hline Faculdade Porto das Águas & Porto Belo & Vale do Itajaí \\
\hline Faculdade Regional Palmitos & Palmitos & Oeste \\
\hline Faculdade Sinergia & Navegantes & Vale do Itajaí \\
\hline Faculdade SOCIESC de Balneário Camboriú & Balneário Camboriú & Vale do Itajaí \\
\hline Faculdade União Bandeirante & São José & Grande Florianópolis \\
\hline Faculdades do Vale do Araranguá & Araranguá & Sul \\
\hline Instituto Blumenauense de Ensino Superior (UniSociesc) & Blumenau & Norte \\
\hline Instituto de Ensino Superior Santo Antônio & Joinville & Norte \\
\hline \multicolumn{2}{|l|}{ SUBOTAL } & 34 \\
\hline \multicolumn{3}{|c|}{ IES PRIVADAS SEM FINS LUCRATIVOS } \\
\hline IES & CIDADE & REGIÃO \\
\hline $\begin{array}{l}\text { Centro Universitário - Católica de Santa Catarina em } \\
\text { Jaraguá do Sul }\end{array}$ & Jaraguá do Sul & Norte \\
\hline $\begin{array}{l}\text { Centro Universitário - Católica de Santa Catarina em } \\
\text { Joinville }\end{array}$ & Joinville & Norte \\
\hline Centro Universitário Barriga Verde & Orleans & Sul \\
\hline Centro Universitário de Brusque & Brusque & Vale do Itajaí \\
\hline Faculdade Anglo-Americano de Chapecó (Santa Rita) & Chapecó & Oeste \\
\hline Faculdade Anhanguera de Joinville & Joinville & Norte \\
\hline Faculdade Anhanguera Jaraguá do Sul & Jaraguá do Sul & Norte \\
\hline Faculdade Avantis & Balneário Camboriú & Vale do Itajaí \\
\hline Faculdade Barddal de Artes Aplicadas & Florianópolis & Grande Florianópolis \\
\hline Faculdade Barddal de Ciências Contábeis & Florianópolis & Grande Florianópolis \\
\hline Faculdade Borges de Mendonça & Florianópolis & Grande Florianópolis \\
\hline Faculdade Católica de Santa Catarina & Florianópolis & Grande Florianópolis \\
\hline Faculdade Cenecista de Joinville & Joinville & Grande Florianópolis \\
\hline Faculdade de Santa Catarina & São José & Norte \\
\hline Faculdade de Tecnologia Assessoritec & Joinville & Grande Florianópolis \\
\hline
\end{tabular}

\begin{tabular}{l|l|l|l|}
\hline (c) Rev. Inter. Educ. Sup. & Campinas, SP & v.4 & n.3
\end{tabular} 


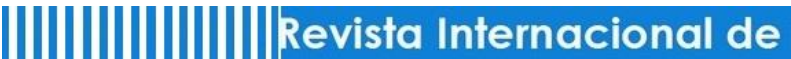

\begin{tabular}{|c|c|c|}
\hline Faculdade de Tecnologia Pedro Rogério Garcia & Concórdia & Oeste \\
\hline Faculdade de Tecnologia SENAC Blumenau & Blumenau & Norte \\
\hline Faculdade de Tecnologia SENAC Caçador & Caçador & Oeste \\
\hline Faculdade de Tecnologia SENAC Chapecó & Chapecó & Oeste \\
\hline Faculdade de Tecnologia SENAC Criciúma & Criciúma & Sul \\
\hline Faculdade de Tecnologia SENAC Florianópolis & Florianópolis & Grande Florianópolis \\
\hline Faculdade de Tecnologia SENAC Jaraguá do Sul & Jaraguá do Sul & Norte \\
\hline Faculdade de Tecnologia SENAC São Miguel do Oeste & São Miguel do Oeste & Oeste \\
\hline Faculdade de Tecnologia SENAC Tubarão & Tubarão & Sul \\
\hline Faculdade de Tecnologia SENAI Blumenau & Blumenau & Norte \\
\hline Faculdade de Tecnologia SENAI Chapecó & Chapecó & Oeste \\
\hline Faculdade de Tecnologia SENAI Florianópolis & Florianópolis & Grande Florianópolis \\
\hline Faculdade de Tecnologia SENAI Palhoça & Palhoça & Grande Florianópolis \\
\hline Faculdade de Tecnologia SENAI Itajaí & Itajaí & Vale do Itajaí \\
\hline Faculdade de Tecnologia SENAI Jaraguá do Sul & Jaraguá do Sul & Norte \\
\hline Faculdade de Tecnologia SENAI Joinville & Joinville & Norte \\
\hline Faculdade de Tecnologia SENAI São José & São José & Grande Florianópolis \\
\hline Faculdade Estácio de Florianópolis - Estácio Florianópolis & Florianópolis & Grande Florianópolis \\
\hline Faculdade FAE Blumenau & Blumenau & Norte \\
\hline Faculdade Guilherme Guimbala & Joinville & Norte \\
\hline Faculdade Luterana de Teologia & São Bento do Sul & Norte \\
\hline Faculdade Refidim & Joinville & Norte \\
\hline Faculdade São Luís & Brusque & Norte \\
\hline Faculdade SATC & Criciúma & Sul \\
\hline Faculdade SOCIESC & Florianópolis & Grande Florianópolis \\
\hline Instituto Cenecista Fayal de Ensino Superior & Itajaí & Vale do Itajaí \\
\hline Instituto de Ensino Superior Grande Florianópolis & São José & Grande Florianópolis \\
\hline $\begin{array}{l}\text { Instituto Superior e Centro Educacional Luterano - Bom } \\
\text { Jesus - IELUSC }\end{array}$ & Joinville & Norte \\
\hline Universidade Comunitária da Região de Chapecó & Chapecó & Oeste \\
\hline Universidade da Região de Joinville & Joinville & Norte \\
\hline Universidade do Extremo Sul Catarinense & Criciúma & Sul \\
\hline Universidade do Oeste de Santa Catarina & Joaçaba & Oeste \\
\hline Universidade do Planalto Catarinense & Lages & Serrana \\
\hline Universidade do Sul de Santa Catarina & Tubarão & Sul \\
\hline Universidade do Vale do Itajaí & Itajaí & Vale do Itajaí \\
\hline Centro Universitário Municipal de São José & São José & Grande Florianópolis \\
\hline $\begin{array}{l}\text { Centro Universitário para o Desenvolvimento do Alto Vale } \\
\text { do Itajaí }\end{array}$ & Rio do Sul & Vale do Itajaí \\
\hline Universidade do Alto Vale do Rio do Peixe & Caçador & Oeste \\
\hline Universidade do Contestado & Mafra & Norte \\
\hline Universidade Regional de Blumenau & Blumenau & Norte \\
\hline \multicolumn{2}{|l|}{ SUBTOTAL } & 54 \\
\hline \multicolumn{3}{|c|}{ IES PÚBLICAS } \\
\hline IES & CIDADE & REGIÃO \\
\hline Faculdade Municipal de Palhoça & Palhoça & Grande Florianópolis \\
\hline Fundação Universidade do Estado de Santa Catarina & Florianópolis & Grande Florianópolis \\
\hline
\end{tabular}

\begin{tabular}{l|l|l|l} 
(C) Rev. Inter. Educ. Sup. & Campinas, SP & v.4 & n.3
\end{tabular} 


\begin{tabular}{|l|l|l|}
\hline $\begin{array}{l}\text { Instituto Federal de Educação, Ciência e Tecnologia de } \\
\text { Santa Catarina }\end{array}$ & Florianópolis & Grande Florianópolis \\
\hline $\begin{array}{l}\text { Instituto Federal de Educação, Ciência e Tecnologia } \\
\text { Catarinense }\end{array}$ & Blumenau & Norte \\
\hline Universidade Federal da Fronteira Sul & Chapecó & Oeste \\
\hline Universidade Federal de Santa Catarina & Florianópolis & Grande Florianópolis \\
\hline SUBTOTAL & & $\mathbf{0 6}$ \\
\hline TOTAL & & $\mathbf{9 4}$ \\
\hline
\end{tabular}

Fonte: elaborado com base nos dados do MEC/INEP, 2016.

Pode-se observar no cenário das IES com oferta de cursos de graduação presencial que as instituições privadas são hegemônicas. Das 94 IES, contabilizadas em 2016, 88 eram privadas, sendo 54 instituições sem fins lucrativos e 34 com fins lucrativos.

A predominância do setor privado também ocorre entre as IES com oferta de graduação EaD. Das 27 IES, relacionadas em 2016, com oferta desta modalidade em Santa Catarina, 24 pertencem ao setor privado, sendo 12 privadas com fins lucrativos e 12 privadas sem fins lucrativos (INEP/MEC, 2016). Quanto as IES públicas com oferta de cursos de graduação na modalidade $\mathrm{EaD}$, em 2016, apenas 3 mantinham este tipo de oferta, a UFSC, o IFSC e a UDESC.

No que diz respeito a organização acadêmica das IES com ensino presencial, a maioria define-se como faculdades (69), correspondendo a 73\% do total. Conforme gráfico abaixo, os centros universitários somam $11 \%$; as universidades $14 \%$ e os institutos federais, $2 \%$.

O gráfico abaixo demonstra como estão distribuídas as IES no quesito da organização acadêmica. 


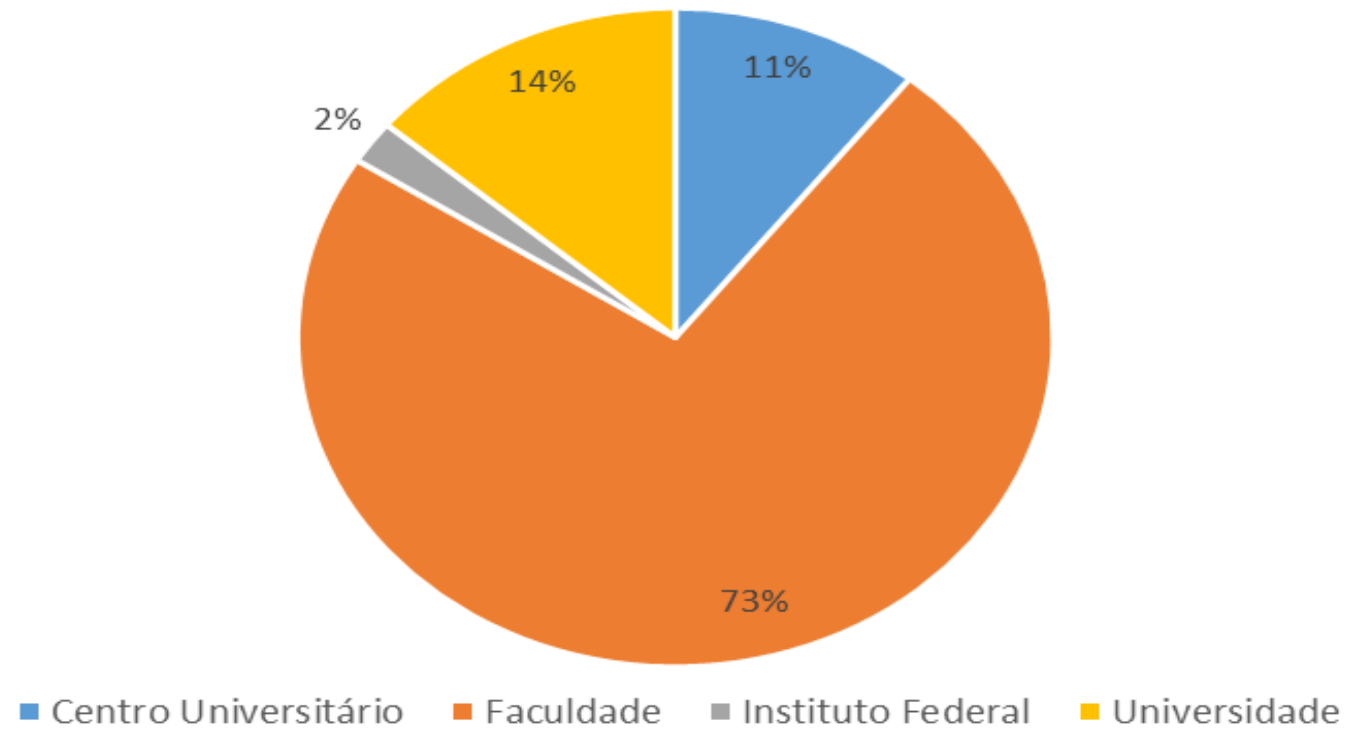

Gráfico 3: Distribuição das IES em Santa Catarina por organização acadêmica em 2016.

Fonte: elaborado com base nos dados MEC/INEP, 2016.

No que diz respeito a organização acadêmica das IES com ensino presencial, a maioria define-se como faculdades (69), correspondendo a 73\% do total. Conforme gráfico anterior, os centros universitários somam $11 \%$; as universidades $14 \%$ e os institutos federais, $2 \%$.

\section{OS CURSOS E AS MATRÍCULAS DA GRADUAÇÃO PRESENCIAL}

O crescimento das matrículas de graduação (presencial e a distância) em Santa Catarina foi exponencial nas últimas décadas. De 47.926 em 1991, saltou para 331.350 em 2016, sendo 230.267 presenciais e 101.083 a distância.

O gráfico abaixo apresenta a evolução do número das matrículas em cursos de graduação na modalidade presencial e a distância no estado de Santa Catarina, no interregno de 1991 até 2016. 


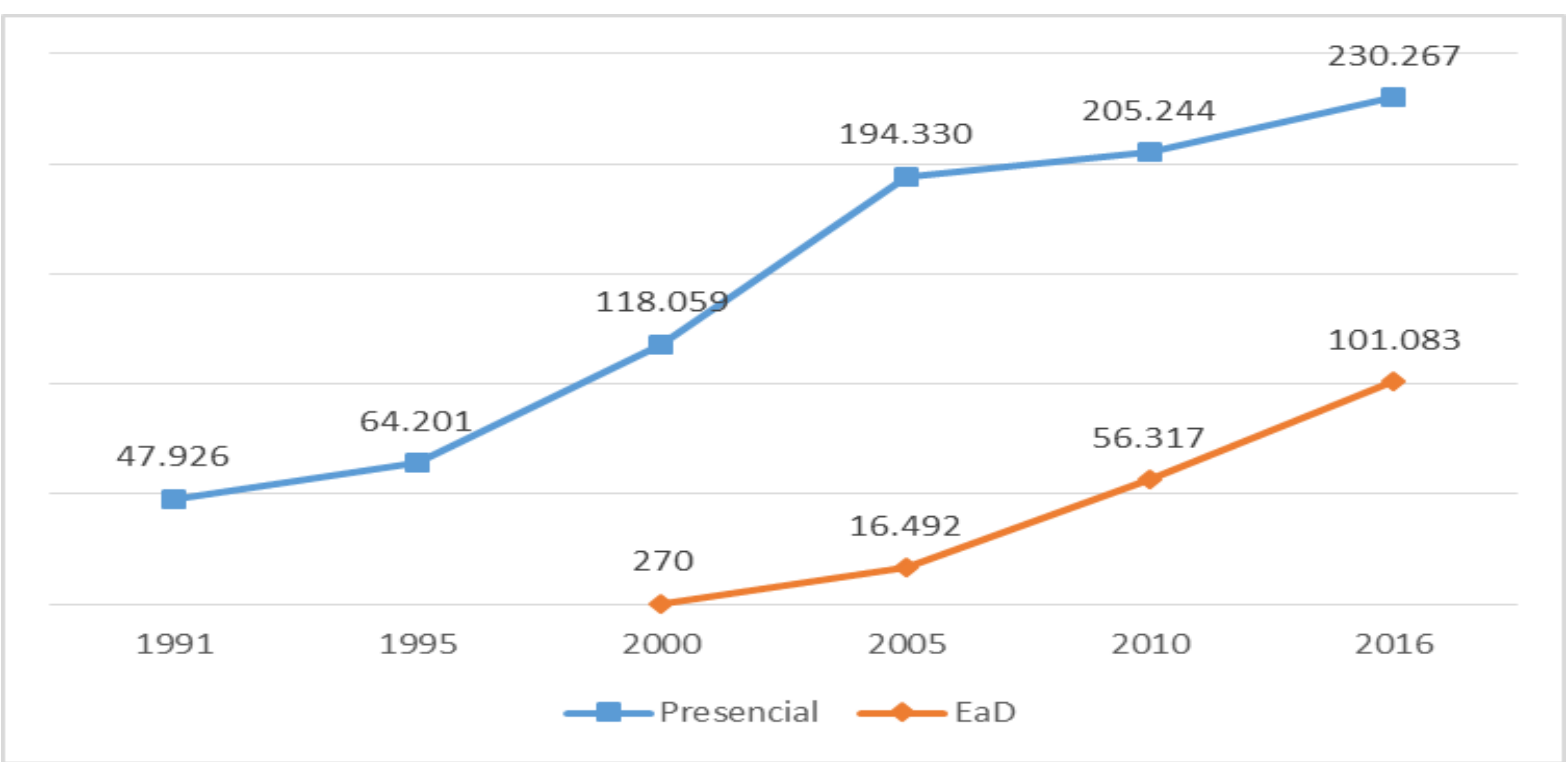

Gráfico 4: Evolução das matrículas em cursos de graduação presencial e a distância em Santa Catarina (1991-2016)

Fonte: elaborado com base nos dados disponíveis em: MEC/INEP/DEAES, 2006 e MEC/INEP, 2016.

Em Santa Catarina, tendo como base o ano de 2016, 68,2\% das matrículas de graduação presencial encontram-se nas instituições privadas. Apenas $31,8 \%$ dos estudantes frequentam IES públicas gratuitas.

Para abrirmos um comparativo entre as modalidades de oferta dos cursos de graduação, temos o seguinte panorama: em 2016, as matriculas presenciais representaram $69,5 \%$ do total de matrículas (331.350). Considerando o período de 2005-2016 as matrículas presenciais cresceram 18,5\%, passaram de 194.330 para 230.267. De outro lado, o ritmo anual de crescimento da modalidade a distância é bastante superior ao verificado na modalidade presencial. Em 2015, a modalidade a distância já respondia por $28 \%$ do total de matrículas no estado. No mesmo período (2005-2016), as matrículas a distância cresceram 512,9\%, passaram de 16.492 para 101.083.

A tabela a seguir indica o crescimento do setor privado na oferta de ensino presencial em Santa Catarina.

Tabela 1: Distribuição das matrículas de graduação presencial em Santa Catarina em 2016, de acordo com a natureza jurídica da IES.

\begin{tabular}{c|c|c|c|c}
\hline ANO & IES PÚBLICAS & \% & IES PRIVADAS & \% \\
\hline 1991 & 39.783 & 83 & 8.143 & 17 \\
\hline 1995 & 57.204 & 89,1 & 6.997 & 11,9 \\
\hline 2000 & 34.629 & 29,4 & 83.430 & 70,6 \\
\hline 2005 & 66.653 & 34,3 & 127.677 & 65,7 \\
\hline
\end{tabular}




\begin{tabular}{l|l|l|l|l}
\hline 2010 & 56.325 & 27,6 & 147.910 & 72,4 \\
\hline 2016 & 73.287 & 31,8 & 156.980 & 68,2 \\
\hline
\end{tabular}

Fonte: elaborado com base nos dados disponíveis em: MEC/INEP/DEAES, 2006 e INEP/MEC, 2016.

Fica evidente uma inversão no número de matrículas entre as categorias. Até 1995 as matrículas em IES Públicas foram significativamente maioria. Contudo, no quinquênio 19952000 as matrículas em IES Privadas cresceram quase 12 vezes e, o crescimento das matriculas neste setor não deixaram mais de crescer, entre 2000 a 2016 o crescimento foi de 88,2\%. Em 2016 as matriculas no setor privado são pouco mais que o dobro do número de matrículas no setor público.

As matrículas em IES Públicas, após queda de -15,5\% no interregno 2005-2010, apresentaram crescimento de 30,1\% no interregno de 2010 a 2016, indo de 56.325 matrículas em 2010, para 73.287 matrículas em 2016. Este crescimento é reflexo das políticas de expansão do setor público como UaB, REUNI e Rede Federal. A despeito da expansão, em 2016 as matrículas das IES públicas correspondiam 31,8\% do total no Estado.

As IES privadas sem fins lucrativos representam 58\% do total das matrículas (133.844 matrículas). Importante destacar que somente as matrículas em IES chamadas de "comunitárias"4 correspondem a 31,7\%. As instituições com fins lucrativos representam 21\% do total de matrículas. Em seguida, as públicas representam $21 \%$, e estão distribuídas em estadual (5\%), federal (16\%) e em municipal (algo em torno de 0,4\%).

\footnotetext{
${ }^{4}$ São instituições comunitárias, conforme previsto na Lei $n^{\mathbf{0}} 12.881 / 2013$, as que apresentam as seguintes características: (i) estão constituídas na forma de associação ou fundação, com personalidade jurídica de direito privado, inclusive as instituídas pelo poder público; (ii) patrimônio pertencente a entidades da sociedade civil e/ou poder público; (iii) não distribuem qualquer parcela de seu patrimônio ou de suas rendas, a qualquer título; (iv) aplicam integralmente no País os seus recursos na manutenção dos seus objetivos institucionais; (v) mantêm escrituração de suas receitas e despesas em livros revestidos de formalidades capazes de assegurar sua exatidão; (vi) possuem transparência administrativa, nos termos dos arts. $3^{\circ}$ e $4^{\circ}$ da Lei $n^{\circ} 12.881 / 2013$; e (vii) preveem a destinação do patrimônio, em caso de extinção, a uma instituição pública ou congênere.

\begin{tabular}{|l|c|c|c|c|c|}
\hline (C) Rev. Inter. Educ. Sup. & Campinas, SP & v.4 & n.3 & p.558-579 & set./dez. 2018 \\
\hline
\end{tabular}
}




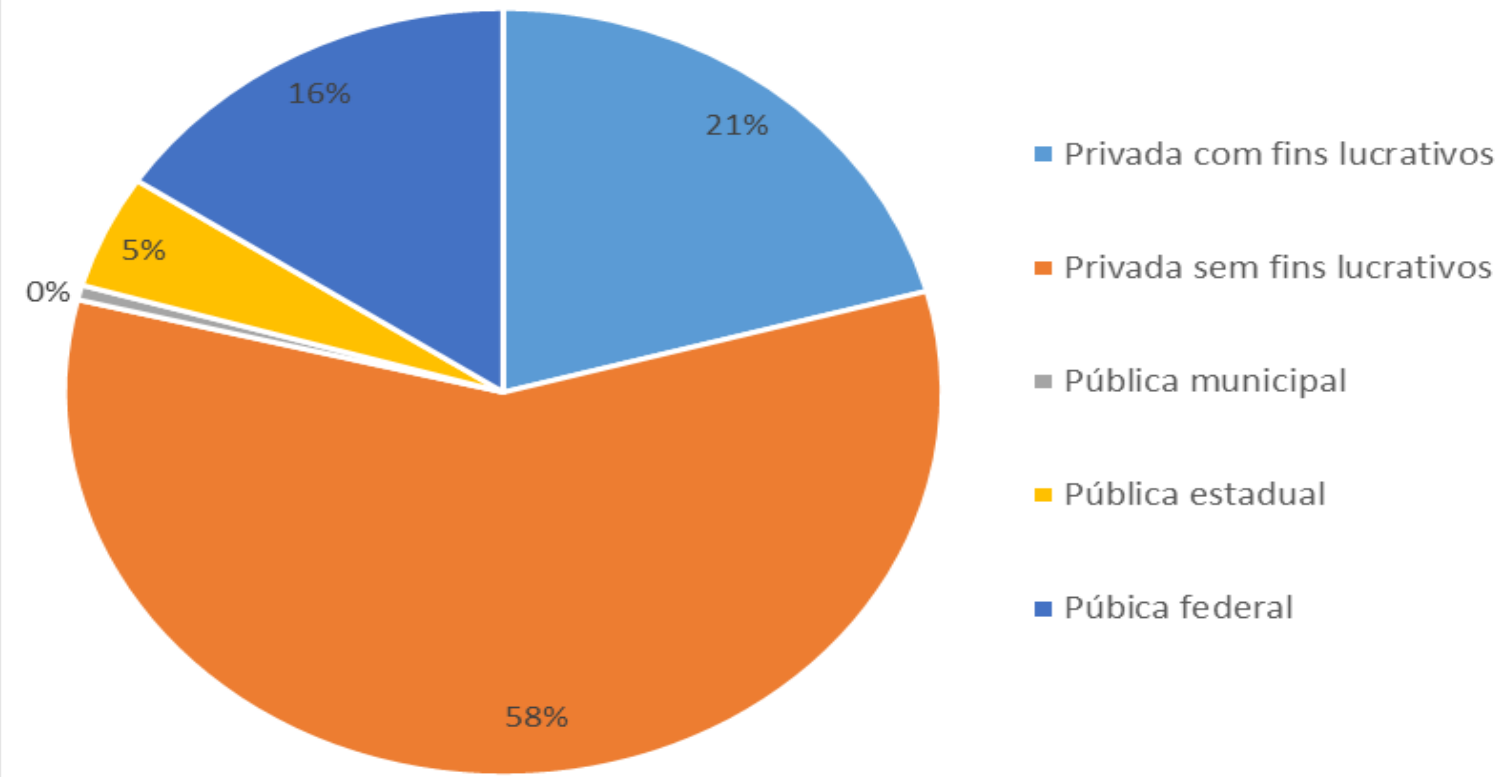

Gráfico 5: Distribuição das matrículas de graduação presencial em Santa Catarina por categoria administrativa, em Santa Catarina, em 2016.

Fonte: elaborada a partir dos dados do MEC/INEP, 2016.

As 230.267 matrículas de graduação presenciais em 2016 em Santa Catarina estavam distribuídas em 1.448 cursos superiores, sendo 67,6\% bacharelados, 15,5\% licenciaturas e $16,9 \%$ tecnólogos.

A tabela a seguir mostra a distribuição do número de cursos de graduação presencial, por grau acadêmico, em Santa Catarina.

Tabela 2: Distribuição do número de cursos de graduação presencial em Santa Catarina, por grau acadêmico (2010-2016)

\begin{tabular}{c|c|c|c|c|c|c}
\hline Ano & \multicolumn{2}{|c|}{ Bacharelado } & \multicolumn{2}{c|}{ Licenciatura } & \multicolumn{2}{c}{ Tecnólogo } \\
\hline & Cursos & Matrículas & Cursos & Matrículas & Cursos & Matrículas \\
\hline $\mathbf{2 0 1 0}$ & 840 & 164.610 & 278 & 22.878 & 246 & 16.747 \\
\hline $\mathbf{2 0 1 1}$ & 866 & 171.064 & 272 & 21.349 & 252 & 17.691 \\
\hline $\mathbf{2 0 1 2}$ & 897 & 177.540 & 285 & 21.127 & 255 & 17.106 \\
\hline $\mathbf{2 0 1 3}$ & 920 & 184.436 & 291 & 21.571 & 248 & 16.298 \\
\hline $\mathbf{2 0 1 4}$ & 932 & 191.338 & 248 & 20.058 & 241 & 15.496 \\
\hline $\mathbf{2 0 1 5}$ & 943 & 197.801 & 248 & 19.923 & 238 & 15.124 \\
\hline $\mathbf{2 0 1 6}$ & 979 & 196.418 & 224 & 19.421 & 245 & 14.428 \\
\hline
\end{tabular}

Fonte: elaborada a partir dos dados do MEC/INEP, 2016.

*Estão excluídos destes dados a categoria de curso "não aplicável”, "sequencial” e as matrículas de "menor 18 anos". 
De acordo com os dados acima, as matrículas dos cursos de bacharelado em 2016 representavam $85,3 \%$ do total das matrículas do ano. Observamos que, quando se trata do crescimento das matrículas na modalidade presencial, os cursos de bacharelado se destacam, no período de 2010 a 2016 cresceram 19,3\%. De outro modo, as matrículas em cursos de licenciatura e tecnologia apresentaram decréscimo, as matrículas nas licenciaturas caíram $15,1 \%$ e, nos tecnólogos caíram $13,8 \%$.

Quanto ao número de cursos na graduação presencial, houve aumento de $16,5 \%$ no número de cursos de bacharelado oferecidos entre 2010 e 2016, do contrário, o número de cursos tecnológicos caíram 0,4\% e os de licenciatura diminuíram 19,4\%. Já na Ead, este cenário se mostra próspero, o número de cursos de bacharelado EaD passou de 302 em 2010, para 800 em 2016. O número de licenciaturas passou de 389 cursos em 2010, para 1.151 cursos em 2016. Por fim, o número de cursos tecnológicos passou de 725 em 2010, para 1.933 em 2016. No geral, a modalidade EaD representa $72,8 \%$ o total de cursos de graduação oferecidos em 2016.

Para analisarmos o panorama das licenciaturas, a tabela abaixo indica os dez cursos de graduação presencial que tiveram os maiores números de estudantes matriculados no período entre 2012 a 2016.

Tabela 3: Os dez cursos de graduação presencial com maior número de alunos matriculados em Santa Catarina (2012-2016)

\begin{tabular}{l|c|c|c|c|c}
\hline \multicolumn{1}{c|}{ CURSO } & $\mathbf{2 0 1 2}$ & $\mathbf{2 0 1 3}$ & $\mathbf{2 0 1 4}$ & $\mathbf{2 0 1 5}$ & $\mathbf{2 0 1 6}$ \\
\hline Direito & 30.783 & 31.790 & 32.942 & 33.824 & 34.264 \\
\hline Administração & 30.160 & 28.352 & 25.811 & 23.965 & 20.930 \\
\hline Engenharia Civil & 8.924 & 11.377 & 13.324 & 14.701 & 14.558 \\
\hline Ciências Contábeis & 13.500 & 13.538 & 13.114 & 12.748 & 11.606 \\
\hline Educação Física & 8.081 & 8.679 & 9.170 & 9.950 & 9.811 \\
\hline Arquitetura e Urbanismo & 5.442 & 6.579 & 7.581 & 8345 & 8.528 \\
\hline Psicologia & 6.732 & 7.207 & 7.563 & 8.017 & 8.229 \\
\hline Engenharia Mecânica & 3.716 & 4.500 & 4.724 & 6.213 & 6.636 \\
\hline Pedagogia & 5.381 & 5.434 & 5.364 & 5.465 & 5.415 \\
\hline Enfermagem & 4.275 & 4.014 & 4.154 & 4.628 & 4.990 \\
\hline
\end{tabular}

Fonte: elaborado com base nos dados do MEC/INEP, 2016.

*Considera-se aqui o número de matrículas para licenciatura e bacharelado.

Como se pode observar, os cursos de Direito e de Administração ocupam, em todos os anos analisados, respectivamente, a primeira e a segunda posições quando o quesito é o número de matrículas. Os dois cursos representam $24 \%$ das matrículas de todos os cursos de graduação, superando, inclusive o total das matrículas de todos os cursos de licenciaturas. Entre os cursos listados acima, a Engenharia Mecânica destaca-se pelo significativo crescimento no período

\begin{tabular}{l|l|l|l|c|c}
\hline (c) Rev. Inter. Educ. Sup. & Campinas, SP & v.4 & n.3 & p.558-579 & set./dez. 2018 \\
\hline
\end{tabular}


2012-2016 (78.6\%). Similar crescimento é verificado na Engenharia Civil $(63,1 \%)$ e na Arquitetura e Urbanismo (56,7\%). Ciências Contábeis teve um decréscimo no período (14\%). Verifica-se também uma redução de matrículas presenciais no curso de Administração (30,6\%), com o destaque de que esse curso vem tendo significativo crescimento na educação a distância. Entre 2010 a 2016, a expansão correspondeu a 71.8\% (de 6.064 para 10.423).

As matrículas em cursos de Licenciatura, na modalidade presencial, representam apenas 8,4\% do total de 230.267 matrículas em cursos de graduação em 2016.

Tabela 4: Número de matrículas em cursos de Licenciatura na modalidade presencial em Santa Catarina, em 2016.

\begin{tabular}{l|c|c|c|c|c}
\hline \multicolumn{1}{c|}{ Curso } & $\mathbf{2 0 1 2}$ & $\mathbf{2 0 1 3}$ & $\mathbf{2 0 1 4}$ & $\mathbf{2 0 1 5}$ & $\mathbf{2 0 1 6}$ \\
\hline Pedagogia & 5.338 & 5.383 & 5.266 & 5.341 & 5.415 \\
\hline Educação Física & 5.319 & 5.316 & 5.185 & 5.292 & 4.917 \\
\hline Matemática & 1.129 & 1.262 & 1.247 & 1.384 & 1.466 \\
\hline História & 1.174 & 1.224 & 1.148 & 1.158 & 1.084 \\
\hline Ciências Biológicas & 1.419 & 1.389 & 1.270 & 1.143 & 1.065 \\
\hline Química & 454 & 608 & 609 & 673 & 804 \\
\hline Física & 677 & 722 & 670 & 683 & 672 \\
\hline Artes Visuais & 794 & 640 & 530 & 474 & 446 \\
\hline Música & 256 & 380 & 369 & 456 & 446 \\
\hline Geografia & 599 & 586 & 446 & 438 & 415 \\
\hline
\end{tabular}

Fonte: elaborado com base nos dados do MEC/INEP, 2016.

Entre as licenciaturas, a Pedagogia ocupa o primeiro lugar, no período analisado, no quesito número de matrículas, a despeito de sua modesta taxa de crescimento $(1,4 \%)$. Verifica-se um significativo crescimento das matrículas dos cursos de Química (77,1\%) e Música (74,2\%). Observa-se redução dos cursos de Artes Visuais (-43,8\%), Geografia (-30,7) e Ciências Biológicas (-24,9\%). O curso de Educação Física teve uma leve redução, cabendo observar que os dados acima se referem ao grau de licenciatura e o curso também é ofertado em grau de bacharelado (MEC/INEP, 2016).

O gráfico a seguir demonstra a evolução da educação superior no estado, considerando as variáveis matrículas, vagas, ingressos e concluintes no período de 2010 a 2016. 


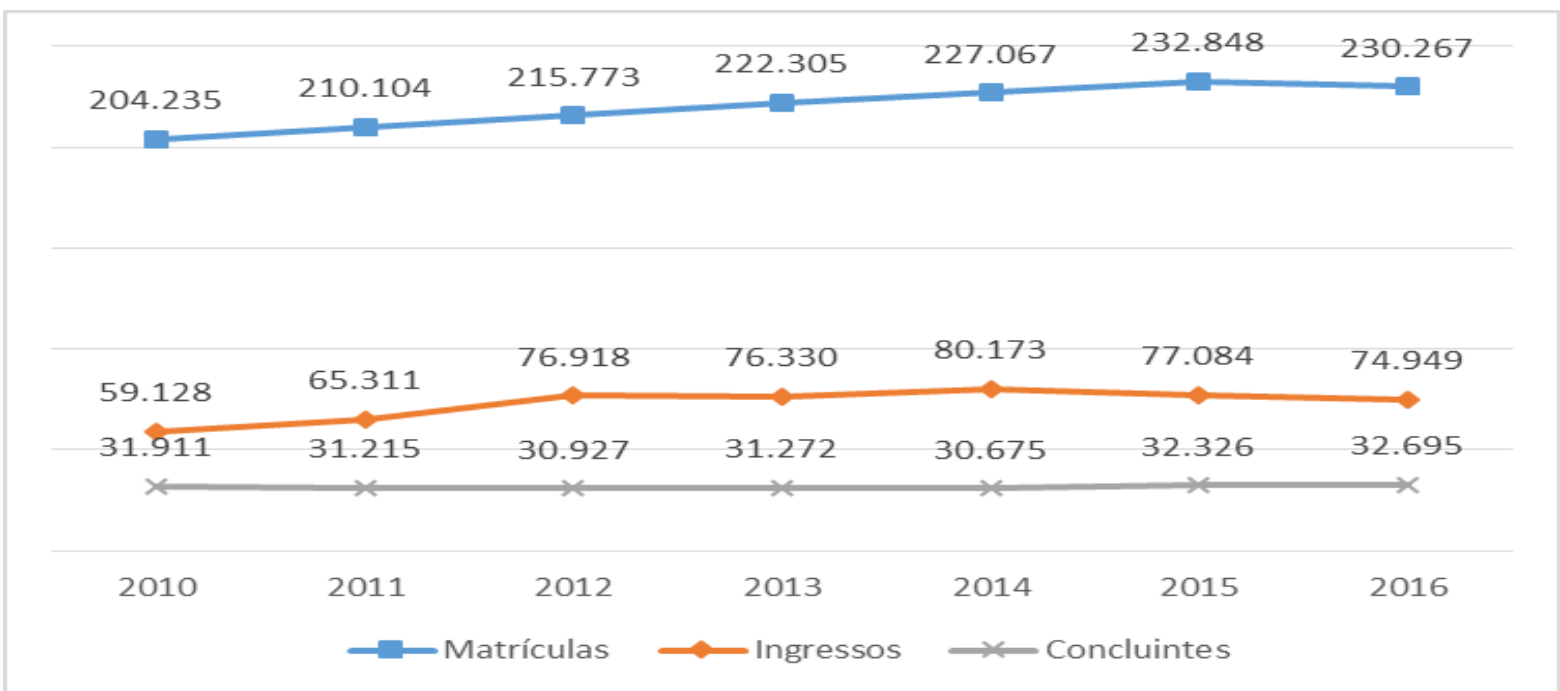

Gráfico 6: Evolução do número de matrículas, vagas, ingressos e concluintes em cursos de graduação presencial em Santa Catarina (2010-2016)

Fonte: elaborado a partir dos dados MEC/INEP, 2016.

*Estão excluídos destes dados a categoria de curso "não aplicável", "sequencial" e as matrículas de "menor 18 anos".

Observamos que o número de alunos matriculas, ingressantes e concluintes entre os anos de 2010 a 2016 experimentaram aumento. As matrículas em cursos de graduação presencial, cresceram $12,7 \%$ no período, o número de alunos ingressantes cresceu $26,8 \%$ e, de concluintes $2,5 \%$.

Para termos um percentual aproximado da evasão/retenção dos alunos durante a realização de seus cursos, consideramos a média de duração de cursos de quatro anos e por isso relacionamos os concluintes de 2016 com os ingressantes de 2013. Desta forma, obtemos um índice de evasão/retenção de 57,2\%.

No tocante às matrículas, chama a atenção também a distribuição segundo o sexo. As mulheres são maioria em todo o período analisado, respondendo por $53,4 \%$ das matrículas; $52,2 \%$ dos ingressantes e $58,5 \%$ dos concluintes.

Tabela 5: Evolução do número de matrículas, ingressos e concluintes em cursos de graduação presencial em Santa Catarina, por sexo (2010-2016)

\begin{tabular}{l|r|r|r|r|r|r}
\hline \multirow{2}{*}{ Ano } & \multicolumn{2}{|c|}{ Matrículas } & \multicolumn{2}{c|}{ Ingressos } & \multicolumn{2}{c}{ Concluintes } \\
\cline { 2 - 7 } & Masculino & \multicolumn{1}{c|}{ Feminino } & Masculino & \multicolumn{1}{c}{ Feminino } & \multicolumn{1}{c}{ Masculino } & Feminino \\
\hline $\mathbf{2 0 1 0}$ & 94.383 & 109.852 & 28.016 & 31.112 & 13.106 & 18.805 \\
\hline $\mathbf{2 0 1 1}$ & 97.600 & 112.504 & 31.595 & 33.716 & 12.932 & 18.283 \\
\hline $\mathbf{2 0 1 2}$ & 100.374 & 115.399 & 36.520 & 40.398 & 12.824 & 18.103 \\
\hline $\mathbf{2 0 1 3}$ & 103.624 & 118.677 & 36.401 & 39.929 & 13.063 & 18.209 \\
\hline
\end{tabular}




\section{Educação Superior [RIESup]}

Artigo

DOI: $10.20396 /$ riesup.v4i3.8651889

\begin{tabular}{l|l|l|l|l|l|l}
$\mathbf{2 0 1 4}$ & 106.077 & 120.990 & 38.658 & 41.515 & 12.701 & 17.974 \\
\hline $\mathbf{2 0 1 5}$ & 109.144 & 123.704 & 36.658 & 41.515 & 13.428 & 18.898 \\
\hline $\mathbf{2 0 1 6}$ & 108.006 & 122.261 & 36.148 & 38.801 & 13.565 & 19.130 \\
\hline
\end{tabular}

Fonte: elaborada a partir dos dados do MEC/INEP, 2016.

*Estão excluídos destes dados a categoria de curso "não aplicável", "sequencial" e as matrículas de "menor 18 anos".

Entre os dez cursos com o maior número de matrículas, as mulheres são maioria em sete deles, cabendo destaque para a Pedagogia (94,6\%), Enfermagem (86,9\%), Psicologia (81,3\%), Arquitetura e Urbanismo (70,3\%), Ciências Contábeis (63,5\%), Direito (56,7\%) e Administração (54\%). Apenas nos cursos de Engenharia Mecânica (91,8\%), Engenharia Civil $(67,8 \%)$ e Educação Física $(57,5 \%)$ os homens são maioria. A presença feminina é particularmente superior nos cursos de licenciaturas, onde as mulheres respondem por $65,3 \%$ das matrículas, $61 \%$ dos alunos ingressantes e $71,7 \%$ dos alunos concluintes.

No que tange à etnia, as matrículas, em 2016, estavam assim distribuídas: 78,7\% (183.296) declarados brancos; 6,8\% (15.903), pardos; 2,6\% (5.991) negros; 0,7\% (1.742) amarelos; e, 0,2\% (465), indígenas. O percentual de matrículas não declarado foi de $11 \%$ (MEC/INEP, 2016).

Do ponto de vista da faixa etária, os estudantes catarinenses são, na sua grande maioria, jovens. A tabela a seguir detalha os percentuais de matrícula de acordo com a idade.

Tabela 6: Evolução do número de matrículas em cursos de graduação presencial em Santa Catarina, por faixa etária (2010-2016).

\begin{tabular}{l|c|c|c|c|c}
\hline \multicolumn{1}{c|}{ Faixa etária } & $\mathbf{2 0 1 0}$ & $\mathbf{2 0 1 2}$ & $\mathbf{2 0 1 4}$ & $\mathbf{2 0 1 6}$ & \% Representação \\
\hline Menor de 18 & 1.244 & 1.503 & 1.421 & 1.261 & $\mathbf{0 , 6}$ \\
\hline 18 anos & 14.999 & 16.814 & 18.655 & 18.094 & $\mathbf{7 , 7}$ \\
\hline De 19 a 44 & 119.635 & 125.462 & 131.742 & 135.738 & $\mathbf{5 7 , 9}$ \\
\hline De 25 a 29 & 38.144 & 39.370 & 40.881 & 40.786 & $\mathbf{1 8 , 0}$ \\
\hline De 30 a 34 & 15.285 & 17.582 & 18.632 & 17.760 & $\mathbf{7 , 8}$ \\
\hline De 35 a 39 & 7.399 & 7.847 & 8.579 & 9.160 & $\mathbf{3 , 7}$ \\
\hline De 40 a 44 & 4.234 & 4.248 & 4.218 & 4.340 & $\mathbf{1 , 9}$ \\
\hline De 45 a 49 & 2.556 & 2.420 & 2.271 & 2.244 & $\mathbf{1 , 1}$ \\
\hline De 50 a 54 & 1.197 & 1.176 & 1.220 & 1.262 & $\mathbf{0 , 5}$ \\
\hline De 55 a 59 & 550 & 558 & 557 & 553 & $\mathbf{0 , 3}$ \\
\hline De 55 a 59 & 550 & 558 & 557 & 553 & $\mathbf{0 , 3}$ \\
\hline De 60 a 64 & 178 & 216 & 229 & 243 & $\mathbf{0 , 1}$ \\
\hline De 65 ou mais & 58 & 80 & 83 & 87 & $\mathbf{0 , 0}$ \\
\hline
\end{tabular}

Fonte: elaborada a partir dos dados do MEC/INEP, 2016. 
Ao longo dos sete anos analisados observou-se que prevalecem em maior número de matrículas os estudantes que se encontram na faixa etária dos 19 aos 24 anos. Outros percentuais significativos são os estudantes de 25 a 29 anos $(18 \%)$, de 30 a 34 anos $(7,8)$ e, de 18 anos $(7,7 \%)$.

\section{CONSIDERAÇÕES FINAIS}

O estudo realizado demonstra que a educação superior catarinense se desenvolveu em ritmos e escalas cujas características e especificidades tornam o estado sui generis em relação aos demais entes da federação. Influenciado pelas políticas e os contextos socioeconômicos nacionais, Santa Catarina fez algumas opções ao longo das décadas, resultando em um conjunto de desdobramentos que, em linhas gerais, permanecem ainda presentes. De forma sintética, as políticas e as diretrizes adotadas impulsionaram ao menos sete principais dinâmicas de desenvolvimento.

O estado de Santa Catarina, em primeiro lugar, promoveu a expansão da educação superior por meio de políticas privatizantes, alicerçadas no financiamento privado e na desresponsabilização do poder público pela oferta da gratuidade. Nos anos 60 , as ações do PLAMEG I, da Secretaria Estadual de Educação e do Conselho Estadual de Educação propiciaram a criação e expansão de um modelo de instituição de ensino superior: as Fundações Educacionais de direito privado, uma modalidade específica de IES criada pelo poder público municipal, de natureza filantrópica e sem fins lucrativos. Em pouco tempo as fundações foram instaladas nas principais cidades do estado. Em 2016, das 94 IES existentes em Santa Catarina, 54 eram privadas sem fins lucrativos, respondendo por cerca de $58 \%$ do total das matrículas (133.844 matrículas).

A educação superior catarinense, em segundo lugar, é predominantemente privada. As instituições privadas (com e sem fins lucrativos) respondiam, em 2016, por $94 \%$ do total das IES e $78,9 \%$ das matrículas de graduação presencial. Nesse ano, as IES públicas e gratuitas representavam $6 \%$ do total de IES, sendo $4 \%$ federais (UFSC, UFFS, IFSC e IFC), $1 \%$ estadual (UDESC) e 1\% municipal (Faculdade Municipal de São José). No quesito matrículas, apesar de o setor público ter apresentado crescimento de 30,1\% no interregno de 2010-2016, ainda representa apenas 30,8\% do total das matrículas. O setor privado foi, por conseguinte, o principal responsável pela expansão do número de IES e de matrículas. A partir do início dos anos 2000, ocorreu um notável crescimento de instituições, passando de 42 em 2000, para 94 em 2016. As matrículas de graduação presencial saltaram de 118.059 em 2000, para 230.267 em 2016. Chama particularmente a atenção o crescimento da EaD. Em 2016, a modalidade respondeu por 30,5\% do total de matrículas no estado. 
O setor privado foi, por conseguinte, o principal responsável pela expansão do número de IES e de matrículas. A partir do início dos anos 2000, ocorreu um notável crescimento de instituições, passando de 42 em 2000, para 94 em 2016.

As matrículas de graduação presencial saltaram de 118.059 em 2000, para 230.267 em 2016. Chama particularmente a atenção o crescimento da EaD. Em 2016, a modalidade respondeu por $30,5 \%$ do total de matrículas no estado. O quarto aspecto observado é que apesar de a maioria dos estudantes catarinenses estarem matriculados em cursos presenciais em Santa Catarina (69,5\%), o ritmo anual de crescimento é bastante superior ao verificado na modalidade presencial. Enquanto o crescimento das matrículas presenciais no período de 2005-2016 foi de 18,5\%, o da educação a distância cresceu 512,9\%.

Um quinto aspecto que chama a atenção é a forte presença das faculdades. Esse formato de organização acadêmica correspondia, em 2016, a 73\% do total das IES catarinenses. As universidades, por conseguinte, somam 14\%; os centros universitários $11 \%$, e os institutos federais, $2 \%$.

Os estudantes catarinenses, em sexto lugar, estão matriculados em cursos de bacharelado. As 230.267 matrículas de graduação presenciais em 2016 em Santa Catarina estavam distribuídas em 1.448 cursos superiores, sendo 979 bacharelados (67.6\%), 224 licenciaturas (15.5\%) e 245 tecnólogos (16.9\%).

Cabe destacar, por fim, a importante expansão das IES públicas a partir do início dos anos 2000. Até 1989, a UFSC manteve-se como a única IES pública e gratuita em Santa Catarina, ano em que a UDESC interrompeu a cobrança de mensalidades e passou a assegurar o princípio da gratuidade. Em 2003, a UDESC aprovou a implantação do Centro de Educação Superior do Oeste (CEO) e, em 2006, os campi de Laguna, Ibirama e São Bento do Sul. Em 2008 foram criados dois Instituto Federais de Educação, Ciência e Tecnologia, o IFSC e o IFC. Em 2009, a UFSC aprovou a criação de seus três primeiros campi nas cidades Araranguá, Joinville e Curitibanos. Nesse ano ocorre também a criação da segunda universidade federal no estado, a Universidade Federal da Fronteira Sul, com sede na cidade de Chapecó. Em 2016 as IES públicas respondiam por 21\% das matrículas da graduação presencial sendo $16 \%$ nas públicas federais (UFSC, UFFS, IFSC e IFC) e $5 \%$ na estadual (UDESC). 


\section{REFERÊNCIAS}

BRASIL. Decreto n ${ }^{\circ}$ 6.096, de 24 de abril de 2007. Institui o Programa de Apoio a Planos de Reestruturação e Expansão das Universidades Federais - REUNI. Diário Oficial da União, Brasília, DF, 24 abr. 2007. Disponível em: <http://www.planalto.gov.br/ccivil_03/_ato20072010/2007/decreto/d6096.htm>. Acesso em: 5 mar. 2016.

DE BASTIANI, Sherlon Cristina. Dinâmicas de desenvolvimento da educação superior na região Oeste de Santa Catarina (1968-2015). 2017. 119 p. (Dissertação de Mestrado) Universidade Federal da Fronteira Sul. Chapecó, SC.

FRANTZ, Walter. Universidade Comunitária: uma iniciativa pública não-estatal em construção. Cadernos Inijuí. Editora: Unijuí, 2004.

FREITAG, Barbara. Escola, estado e sociedade. São Paulo: Moraes, 1980.

HAWERROTH, Jolmar Luis. A expansão do ensino superior nas universidades do sistema fundacional catarinense. Florianópolis: Insular, 1999.

IBGE. Fundação Instituto Brasileiro de Geografia e Estatística. População de Santa Catarina. 2017. Disponível em:

https://ww2.ibge.gov.br/home/mapa_site/mapa_site.php\#populacao. Acesso em: fev. 2018.

MEC/INEP. Censo da Educação Superior 2016. Disponível em:

<http://portal.inep.gov.br/web/censo-da-educacao-superior>. Acesso em: 01 jul. 2017.

MEC/INEP. Censo da Educação Superior 2016. Principais resultados. Disponível em: http://download.inep.gov.br/educacao_superior/censo_superior/documentos/2016/censo_supe rior_tabelas.pdf. Acesso em: 12 fev. 2018a.

MEC/INEP. Censo da Educação Superior 2016. Notas estatísticas. Disponível em: http://download.inep.gov.br/educacao_superior/censo_superior/documentos/2016/notas_sobre _o_censo_da_educacao_superior_2016.pdf. Acesso em: 12 fev. 2018 b.

MEC/INEP/DEAES. Educação Superior Brasileira 1991-2004. Santa Catarina. Brasília: INEP, 2006.

MUNIZ, M. D. Educação superior em Santa Catarina: consolidação e expansão. 2006, 261 p. (Doutorado em Engenharia de Produção) - Universidade Federal de Santa Catarina, Florianópolis.

PEGORARO, Ludimar. O terceiro setor e o ensino superior no Brasil: o sistema fundacional catarinense. In.: PERONI, Vera Maria Vidal et al. (Org.). Dilemas da educação brasileira em tempos de globalização neoliberal: entre o público e o privado. Porto Alegre: Editora da UFRGS, 2006. 
PEGORARO, Ludimar. Terceiro setor na educação superior brasileira. Campinas: Leitura Crítica, 2013.

VEDANA, Léa Maria Ferreira. A educação em Santa Catarina nos anos 60. Revista Esboços, v.5, n. 5. Jun./Dez. 1997. Disponível em: <https://periodicos.ufsc.br/index.php/ esbocos/article/view/524>. Acesso em: 15 fev. 2018.

SAMPAIO, Helena. O ensino superior no Brasil: o setor privado. São Paulo: Hucitec, 2000.

SANTA CATARINA. Lei no 2.772, de 21 de julho de 1961. Dispõe sobre o Plano de Metas do Governo Estadual sobre o quinquênio 1961/1965, institui fundos, unifica tributos, autoriza a constituição de sociedades existentes, a assinatura de convênios, cria secretaria de estado e dá outras providências. Disponível em: <http://leisestaduais.com.br/sc>. Acesso em: 15 fev. 2018.

SANTOS, Milton. O lugar e o cotidiano. In: SANTOS, B. de S.; MENEZES, M. P. (Org). Epistemologias do Sul. São Paulo: Cortez, 2010.

SAVIANI, Dermeval. História das ideias pedagógicas no Brasil. São Paulo: Autores Associados, 2007.

TREVISOL, Joviles V. O ensino superior público na Mesorregião Fronteira Sul: a implantação da UFFS. In: RADIN, José C.; VALENTINI, Delmir J.; ZARTH, Paulo A. História da Fronteira Sul. Porto Alegre: Letra\&Vida; Chapecó: UFFS, 2015a.

TREVISOL, Joviles. A pós-graduação na Universidade Federal da Fronteira Sul: interiorização e redução de assimetrias em uma Região de fronteira. Revista Brasileira de Pós-Graduação, Brasília, v. 12, n. 28, p. 505-532, ago. 2015b. Disponível em: <http://ojs.rbpg.capes.gov.br/index.php/rbpg/article/view/781>. Acesso em: 15 fev. 2018.

\footnotetext{
Sobre os autores

${ }^{1}$ Sherlon Cristina De Bastiani $(\mathbb{D}$

E-mail: sherlondebastiani@gmail.com

Rede Pública Municipal de Joaçaba - Brasil

Mestre em Educação pela Universidade Federal da Fronteira Sul [UFFS].

${ }^{2}$ Joviles Vitório Trevisol $\mathbb{D}$

E-mail: joviles.trevisol@uffs.edu.br

Universidade Federal da Fronteira Sul - Brasil

Pós-Doutor em Sociologia pela Universidade de Coimbra.
} 